\title{
Hepatitis B virus infection in Singapore
}

\author{
R Guan
}

\begin{abstract}
Although Singapore is in an endemic region for hepatitis $B$ infection, the hepatitis $B$ carriage rate of $5-6 \%$ is relatively low. The highest positivity rates for hepatitis B surface antigen (HBsAg) are found in the paediatric age group, with another peak in $40-49$ year olds. Studies suggest that, although perinatal transmission is an important route of infection, most children acquire the virus through horizontal transmission between family members. Viral replication continues at a high rate in young carriers and tends to slow down with increasing age. Up to $50 \%$ of hepatitis B carriers in Singapore have chronic hepatitis, shown by raised serum ALT values and liver histology, and about $10 \%$ are infected with the precore mutant virus. About $20 \%$ of carriers have cirrhosis. Among patients with HCC, up to $75 \%$ are $\mathrm{HBsAg}$ positive, of whom $45 \%$ are still viraemic. Mass vaccination against hepatitis B was introduced into Singapore on a voluntary basis in 1983 , with compulsory vaccination of babies born to $\mathrm{HBeAg}$ positive mothers since 1985 . The number of cases of acute hepatitis $B$ has fallen by $60 \%$ between 1989 and 1995 although the problems of the longterm complications of chronic hepatitis B still need to be tackled.
\end{abstract}

(Gut 1996; 38 (suppl 2): S13-S17)

Keywords: hepatitis B, epidemiology, hepatocellular carcinoma, Singapore.

Singapore is a tropical island state situated at the southern tip of the Malay Peninsular. It has an area of 626 square kilometres. Singapore is very cosmopolitan in its population and culture. At the last census count about 10 years ago, there were approximately 2.5 million people living on this island with a male:female ratio of about one. The majority of the population is Chinese in origin (77\%), followed by Malays (15\%) and Indians (6\%). The remainder $(2 \%)$ are Europeans, EuroAsians, and Japanese.

Although Singapore is in an endemic region for hepatitis $\mathbf{B}$ infection, ${ }^{12}$ the hepatitis B carriage rate of 5-6\% (approximately 150000 carriers) is relatively low. The incidence of acute hepatitis B virus (HBV) infection has declined by about $63 \%$ since 1989 , falling from 291 symptomatic cases to 133 in 1993 and 109 in $1994 .^{3}$ About $30 \%$ of acute infections are imported. $^{3}$ Cases are considered to be imported when the suspected date of contact with the disease, based on the known incubation period, corresponds with the period when the patient was away from Singapore, usually in the surrounding countries and in the Indian subcontinent. The incidence of hepatocellular carcinoma (HCC) among men is 28 per 100000 per year. This is a relatively high figure and reflects the cohort of hepatitis B carriers that has reached the age when cancer occurs. ${ }^{4}$

\section{Epidemiology}

PREVALENCE

Local data collected prior to the introduction of mass hepatitis $B$ vaccination suggested that $\mathrm{HBV}$ infection starts early in life, giving rise to particularly high carrier rates, continuance of $\mathrm{HBV}$ infection into adult life, and a predominance of subclinical infections. ${ }^{5}$ Table I shows the hepatitis B surface antigen ( $\mathrm{HBsAg}$ ) carrier rates among the different ethnic groups. The carrier rates among pregnant women probably reflect the carrier rates of women generally. ${ }^{5}$ Figure 1 shows the age specific prevalence of HBV markers in the general population in Singapore. Sera were obtained from 569 normal adult volunteers and 272 children aged between 1 and 12 years who had been admitted to a major paediatric ward for illnesses not associated with the liver. ${ }^{4}$ The frequency of HBsAg positivity was highest among the paediatric age group. Numbers fell in the teenage group, and there was then a slow rise, subsequently peaking in 40-49 year olds. The frequency of antibodies against HBsAg (antiHBs) and antibodies against hepatitis B core antigen (anti-HBc) showed a progressive increase with age, reaching about $50 \%$ in $40-49$ year olds and $100 \%$ in subjects over 60 years of age.

\section{ACUTE HEPATITIS}

Acute hepatitis B is very uncommon in childhood and is predominantly a disease of male adolescents. About $20 \%$ to $30 \%$ of cases of acute $\mathrm{HBV}$ infection are imported and are usually the result of sexual transmission. ${ }^{3}$ Needle stick injuries probably play a minor part in HBV transmission nowadays, although they may have played a major part in the past, either through parenteral injections using nondisposable needles or through acupuncture. Outbreaks of acute hepatitis B have also been traced to tattoo parlours between 1977 and

TABLE I Hepatitis B carrier rates in different ethnic TABLE I Hepatitis $B$
groups in Singapore

\begin{tabular}{lll}
\hline & Blood donors (male) & Pregnant women \\
\hline Chinese (\%) & $13 \cdot 6$ & $6 \cdot 2$ \\
Malays (\%) & $7 \cdot 3$ & $2 \cdot 3$ \\
Indians (\%) & 6.0 & 0.6
\end{tabular}

Mount Elizabeth National University 


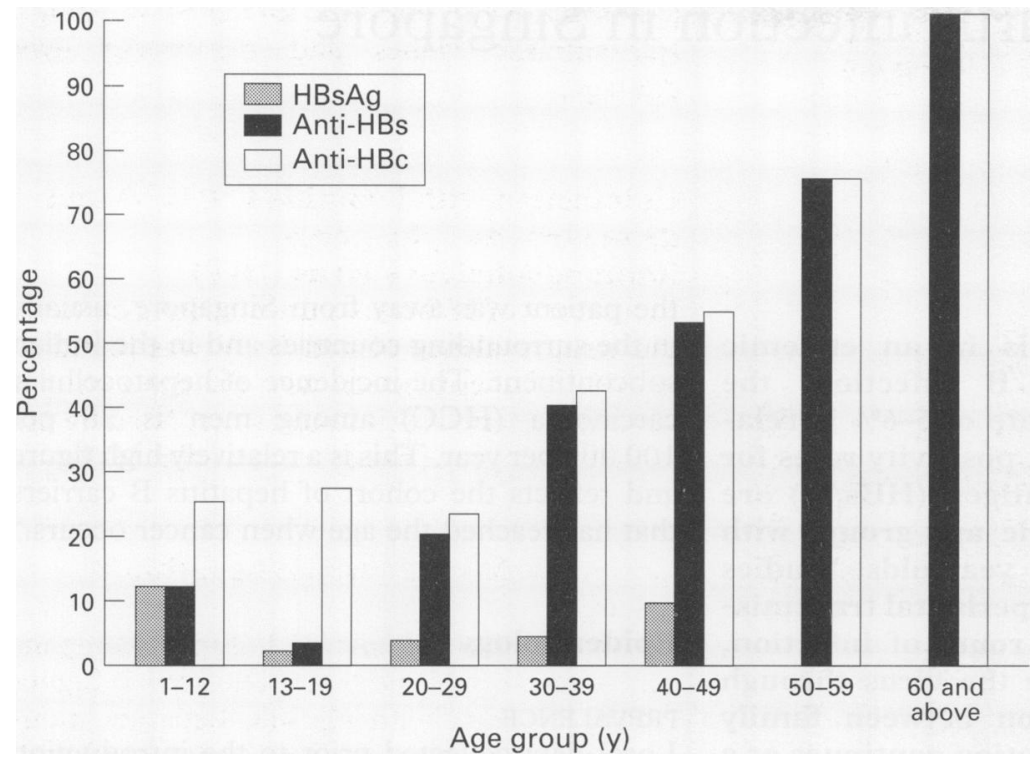

Figure 1: Age specific markers of HBV infection in Singapore. ${ }^{5}$

1981.6 Transmission of HBV infection through blood transfusion is rarely seen since the introduction of routine blood donor screening for HBsAg in the late 1970s.

\section{TRANSMISSION}

The HBV carrier pool in endemic areas is largely made up of people who acquired their infection during infancy and childhood, when the probability of developing chronic infection is the highest. ${ }^{7}$ Most infections transmitted from carrier mothers to their children - either at birth or shortly thereafter - are asymptomatic, and hence remain undetected. Studies from Taiwan have shown the importance of perinatal transmission in the intrafamilial spread of HBV infection in this region. ${ }^{8}$

Between June 1980 and June 1982, Chan and his colleagues studied the babies of 58 HBsAg carrier mothers at delivery and followed up 56 of these infants for at least one year. ${ }^{9}$ Overall, HBV transmission occurred in 27 of $56(48 \%)$ infants; intrauterine infection and infection after the perinatal period each accounted for $8 \%$ of the cases. Nineteen of 56 infants remained $\mathrm{HBsAg}$ positive at 1 year, giving a carrier rate of $34 \%$ in the study population. The carrier rate among pregnant mothers was $4.4 \%$. This would give a carrier prevalence of only $1.6 \%$ among Singapore infants $(34 \%$ of $4 \cdot 4 \%)$. However, a serological study of 458 children admitted to a major paediatric department in Singapore at around the same time showed that the prevalence of HBsAg carriers among Singapore infants was $8.9 \%$ (17 of 186$).{ }^{10}$ This was much higher than the calculated figure of $1.6 \%$ obtained above. The majority of infant HBV infection, therefore, must have occurred by horizontal transmission.

A recent serological survey performed on 270 family members of 78 hepatitis B carriers showed that the chances of children of carrier parents being HBsAg positive were similar whether the carrier parent was the father or the mother. ${ }^{11}$ The proportions of siblings and parents of HBV carriers who were HBsAg positive were also similar to those of carriers' children. Spouses were less likely to be HBsAg positive when compared with children of carrier fathers or siblings of index patients. In this study, it was also found that the hepatitis B e antigen ( $\mathrm{HBeAg}$ ) status of index subjects did not affect the proportions of parents or children who were HBsAg positive or had markers of previous HBV exposure. However, siblings of $\mathrm{HBeAg}$ positive index subjects were more likely to be positive for $\mathrm{HBsAg}$ and more likely to have markers of previous exposure when compared with siblings of HBeAg negative index cases. The above findings suggest the importance of horizontal transmission among siblings in a family group. ${ }^{11}$

\section{Natural history of childhood acquired chronic hepatitis $B$ infection}

AGE OF INFECTION

The natural history of chronic hepatitis B infection in Singapore is similar to that seen in other countries in the region. In most cases, infection starts early in life, giving rise to a high prevalence of chronic $\mathrm{HBV}$ carriage. Viral replication continues at a very high rate in young subjects and tends to slow down with increasing age. Young, asymptomatic $\mathrm{HBeAg}$ positive carriers sometimes progress to chronic hepatitis, while a proportion of them undergo spontaneous seroconversion to anti-HBe antibody positivity without developing liver disease. Viral replication is significantly reduced with the development of anti-HBe antibodies. Older hepatitis B carriers are usually asymptomatic and anti-HBe positive but those who are $\mathrm{HBeAg}$ positive usually have more severe liver disease.

\section{VIRAL MARKERS}

In a report from the National University Hospital in Singapore, 404 consecutive hepatitis B carrier patients aged 3-85 years were studied over a five year period. ${ }^{12}$ At presentation, 177 (44\%) patients were $\mathrm{HBeAg}$ positive and $217(54 \%)$ patients were anti-HBe positive. The remaining $10(2 \%)$ patients were negative for both e markers. HBV-DNA was detected in the serum of $169(42 \%)$ patients, including $85 \%$ of $\mathrm{HBsAg}$ positive patients and $9 \%$ of $\mathrm{HBeAg}$ negative patients. Figure 2 shows the frequencies of $\mathrm{HBsAg}$ positivity according to age. There was a tendency for patients to lose their $\mathrm{HBeAg}$ with increasing age. $\mathrm{HBeAg}$ positive patients were generally found to have higher mean serum ALT values (75 IU/l) compared with those who were HBeAg negative $(46 \mathrm{IU} / \mathrm{l})(\mathrm{p}<0.001)$.

\section{HISTOLOGY}

Liver histology was available in 135 patients in the above study. ${ }^{12}$ Minimal changes were found in 53 patients (39\%). Chronic hepatitis (chronic persistent hepatitis, chronic lobular 


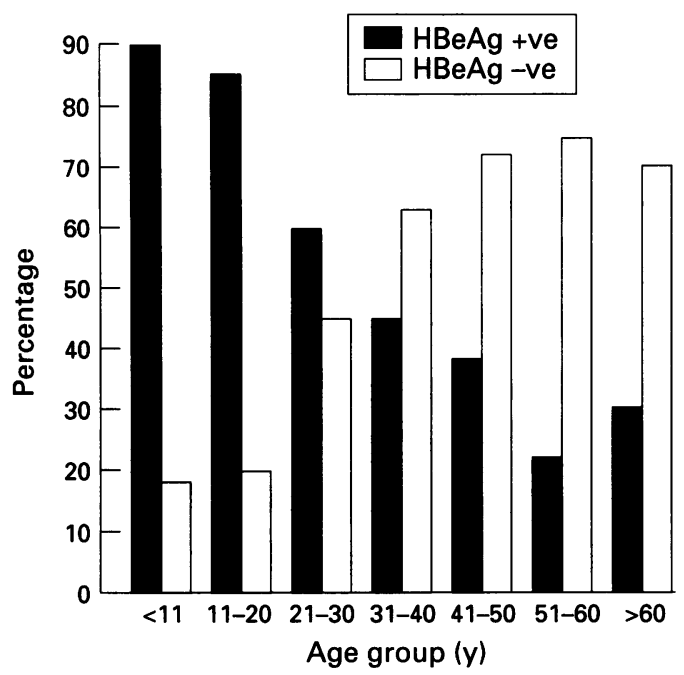

Figure 2: Frequency of $\mathrm{HBeAg}$ positive/negative status according to age groups in Singapore. ${ }^{12}$

hepatitis, and chronic active hepatitis) was seen in $61(45 \%)$ patients, and $21(16 \%)$ had liver cirrhosis.

\section{LONGTERM FOLLOW UP}

Two hundred and fifty eight patients were followed up for a mean duration of two years (range 3-108 months). ${ }^{12}$ Of these, 101 were $\mathrm{HBeAg}$ positive. The cumulative probability of clearing $\mathrm{HBeAg}$ at the end of the first, second, and third years of follow up was $14 \%, 16 \%$, and $18 \%$, respectively. Among those who lost $\mathrm{HBeAg}$, the cumulative probability of developing anti-HBe over one, two, and three years was $8 \%, 9 \%$, and $11 \%$, respectively. Reappearance of $\mathrm{HBeAg}$ occurred in $1.5 \%$ of patients who were $\mathrm{HBeAg}$ negative at presentation and in $1 \%$ of $\mathrm{HBeAg}$ positive patients who had cleared $\mathrm{HBeAg}$ during follow up. HBV-DNA was detected intermittently in $9 \%$ patients with anti-HBe. Four $(1 \cdot 5 \%)$ patients underwent $\mathrm{HBsAg}$ seroconversion to anti-HBs within five to 30 months (mean 15 months) of follow up, all of whom were over 40 years of age.

\section{Precore mutant infection}

About $10 \%$ of patients with chronic hepatitis B infection in Singapore harbour the $\mathrm{HBeAg}$ negative $\mathrm{HBV}$ variant resulting from a mutation in the precore region of the viral genome. ${ }^{12}$ Most infections with this variant are asymptomatic. They have been found to occur even before seroconversion to anti-HBe has occurred. Precore mutant infection becomes clinically significant in the older $\mathrm{HBeAg}$ positive hepatitis B carrier, and is usually

TABLE II Histological features of 135 chronic hepatitis $B$ patients $^{12}$

\begin{tabular}{lclr}
\hline & Total & HBeAg+ve & HBeAg-ve \\
\hline Minimal changes (\%) & $53(39)$ & $31(36)$ & $22(46)$ \\
Chronic hepatitis (\%) & $61(45)$ & $44(50)$ & $17(35)$ \\
Cirrhosis (\%) & $21(15)$ & $12(14)$ & $9(19)$ \\
Total (\%) & $125(100)$ & $87(64)$ & $48(36)$ \\
\hline
\end{tabular}

associated with episodic increases in serum transaminase values and continuing liver damage.

Coinfection with hepatitis C (HCV) and delta virus and the human immunodeficiency virus (HIV)

In a survey of 188 consecutive HBsAg carriers, the seroprevalence of anti-HCV was found to be $3 \% .{ }^{13}$ Superinfection with the delta virus is virtually absent in this island state. No data are available on the coinfection rate with HIV.

\section{Complications of chronic hepatitis B infection}

The frequency of hepatitis B surface antigenaemia has been found to be significantly higher among patients with chronic hepatitis, nonalcoholic cirrhosis, and HCC compared with the normal local population. ${ }^{5}$

\section{CHRONIC HEPATITIS}

Up to $50 \%$ of hepatitis B carriers have chronic hepatitis, confirmed by raised serum ALT values and liver histology. ${ }^{12}$ These patients are usually asymptomatic but may present with lethargy. The diagnosis is usually suspected as a result of persistently raised serum transaminase values.

\section{CIRRHOSIS}

Cirrhosis is seen in about $20 \%$ of HBV carriers locally. Macronodular cirrhosis occurs after a few years in patients with hepatitis B e antigenaemia and continuing liver disease activity (as shown by persistently raised transaminase values) and in those subjects with multiple attempts at seroconversion to anti$\mathrm{HBe}$. Not all patients with cirrhosis have decompensated disease, although no figures are available. About $1 \%$ of patients with cirrhosis develop HCC yearly. ${ }^{4}$

\section{HEPATOCELLULAR CARCINOMA}

HCC is a late complication of chronic hepatitis $\mathrm{B}$ infection. HBsAg is present in up to $75 \%$ of patients with HCC in Singapore ${ }^{514}$ and up to $97 \%$ of patients with HCC have been found to have evidence of previous $\mathrm{HBV}$ infection. ${ }^{15} 16$ In a recent study in $60 \mathrm{HBsAg}$ positive patients with HCC, $45 \%$ were still viraemic. ${ }^{16}$ This was a significantly higher rate than that found in $\mathrm{HBsAg}$ positive age and sex matched controls, indicating the possible role of continuing HBV activity in the pathogenesis of HBV related HCC. Exposure to aflatoxin is not an important factor in the pathogenesis of HCC locally. ${ }^{1718}$

A review of 104 cases of HCC seen at the National University Hospital over a two year period, from January 1988 to December 1989, showed that most patients were over 60 years of age. ${ }^{15}$ Hepatomegaly with features of cirrhosis was the main physical finding and pain the main symptom. Many patients were not 
suitable for curative resection at presentation and all of these died within two years of diagnosis. Chemotherapy did not seem to improve survival. Ten patients underwent successful resections, but two of them died one year later - one from liver failure and the other from disease recurrence. Four patients were still alive and had been followed up for a mean duration of 18 months (range 7-34 months) when the study was published.

Because of the unresectable nature of the lesion at clinical presentation, attempts have been made at early detection of HCC in high risk patients by frequent measurements of serum $\alpha$ fetoprotein and liver ultrasound, and this has resulted in increased numbers of resectable tumours. It is, however, an expensive measure and may not be cost effective. 1920

\section{Treatment}

The aim of treatment of patients with chronic $\mathrm{HBV}$ infection is to eliminate viral replication and hence to prevent liver damage. Elimination of HBV with successful treatment is rare in this part of the world. Treatment in the early stages of chronic infection, when liver histology does not show any inflammatory activity, has been uniformly dismal using the usual treatment regimens practised in the West. $^{21-23}$ The reasons for the relative insensitivity of this group of patients to treatment are not entirely known. It has been suggested that the failure to respond to the presently available modality of treatment (alpha interferon) is because of immunotolerance of the body to the virus. ${ }^{21}$ Cell mediated immunity has been found to be normal in asymptomatic HBV carriers locally, 2425 with no reduction in the ability of their peripheral blood mononuclear cells to produce alpha or gamma interferon. ${ }^{26}$ Nevertheless, patients with chronic hepatitis B and raised liver transaminase values do respond to interferon therapy in the same manner as patients in the West. ${ }^{27}$ Patients with precore mutant infections can be easily treated with small doses of interferon. Furthermore, the problem of relapse is not as common in Singapore as in the West.

\section{Prevention}

Before the availability of hepatitis B vaccine, prevention and control were based entirely on sanitary precautions and personal health education. These included routine screening of blood donors for HBsAg, introduction of disposable syringes and needles, sterilisation of medical and dental equipment, and surveillance of tattoo parlours and acupuncture clinics. There was a significant decline in the proportion of chronic hepatitis B cases with a history of parenteral exposure from $62 \%$ in 1977 to $29 \%$ in 1988 . Post-transfusion and tattoo associated acute hepatitis B were virtually eliminated. Mass hepatitis B vaccination was introduced into Singapore on a voluntary basis in 1983, starting with health care workers. $^{28}$ Compulsory vaccination of babies born to HBsAg positive mothers since 1985 has reduced the number of new carriers. ${ }^{29}$

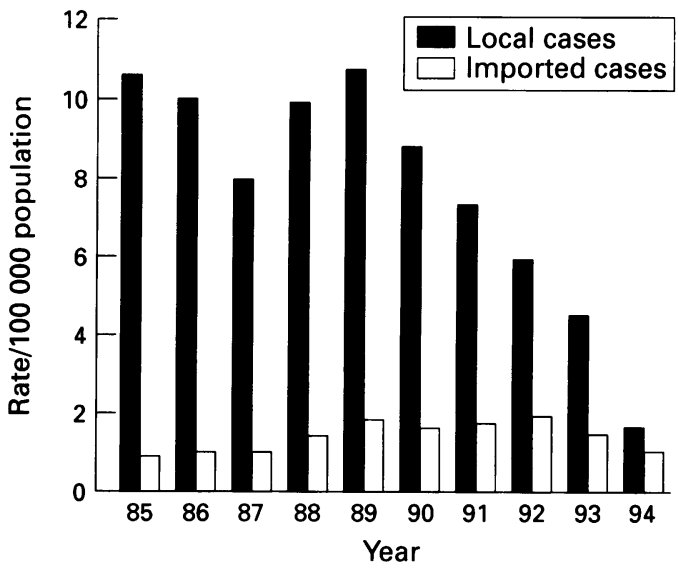

Figure 3: Morbidity rate of reported acute hepatitis $B$ cases in Singapore. ${ }^{3}$

Hepatitis B vaccination is now being recommended for the following groups of people: health care workers, inmates of homes for the intellectually impaired, and people at risk from direct contact with infected people.

Due to the initial high cost of the vaccine, studies using reduced doses of vaccine were performed both in infants and adults. These studies showed that the reduced doses were as effective as the manufacturer's recommended dose. ${ }^{30} 31$ Antibody values, however, were much lower than those achieved using the manufacturer's recommended regimen. Despite this, persistence of antibodies was similar to that achieved using the recommended doses. ${ }^{29} 32$

No local figures are available on the number of people vaccinated with the hepatitis $B$ vaccine. In view of the prevalence of hepatitis $B$ infection locally, it is recommended that hepatitis B serology be performed before vaccination is given. Vaccinating a carrier is harmless but wasteful and gives a false sense of security, although a recent study in France has shown that vaccination of such individuals may have therapeutic implications. ${ }^{33}$ On the one hand, vaccination would boost anti-HBs values in those already immune. On the other hand, however, vaccination is been shown to give rise to vaccine escape mutants. ${ }^{34} 35$ In 1990, Carmen and colleagues reported a point mutation in residue 145 (predicting a change from glycine to arginine) in the second loop of the ' $a$ ' determinant of the surface genome in an infant from southern Italy. ${ }^{34}$ Four similar cases were later identified in Singapore and Japan. ${ }^{35}$ All these infants were born of $\mathrm{HBeAg}$ positive mothers and all had vaccination together with immunoprophylaxis. Horizontal transmission of these mutants has not been proved.

Figure 3 shows the impact of hepatitis $B$ vaccination on the incidence of chronic hepatitis $B$ infection in Singapore. The number of acute cases has fallen by $60 \%$ between 1989 and $1995 .^{3}$ The impact of vaccination on the incidence of HCC will not be evident until about 20 years' time.

\section{Conclusion}

Hepatitis $B$ vaccination is preventing mother to child transmission of hepatitis $B$ infection 
and stemming the source of the carrier pool locally. The problem of the longterm complications of chronic hepatitis B infection notably cirrhosis and HCC - still needs to be tackled. To date, the only effective treatment for chronic hepatitis B infection is alpha interferon, and this is appropriate in only about $30-40 \%$ of chronic hepatitis $\mathrm{B}$ infections locally. Clinical trials using nucleoside analogues seem promising. Both these agents reduce $\mathrm{HBV}$ replication and therefore the infectivity of the affected person and the disease activity in the liver. Complete elimination of HBV is not always possible with the currently available therapeutic agents. New classes of drugs are urgently needed, especially for those patients in the early stages of the disease.

1 Chan SH. Hepatitis B infection in Singapore. Epidemiological News Bulletin 1977; 3: 15.

2 Goh KT. Hepatitis B surveillance in Singapore. Ann Acad Med Sing 1980; 9: 136-41.

3 Goh KT. Acute hepatitis B surveillance in Singapore. Epidemiological News Bulletin 1995; 21: 33-4.

4 Lee HP, Day NE, Shanmugaratnam K. Trends in cance incidence in Singapore 1968-1982. International Agency for Research in Cancer, Geneva. World Health Organization. IARC Sci Publ 1988: 91.

5 Chan SH, Oon CJ. Epidemiology of HBV infection in Singapore. Asian Pacific F Allergy Immunol 1984; 1 : 139-43.

$6 \mathrm{Goh}$ KT. Surveillance of chronic hepatitis B. In Epidemiology and control of hepatitis B virus infection in Singapore. Southeast Asian Medical Information in Singapore. Southeast Asian Medical Information Centre,

7 Coursaget P, Yvonnet B, Chotard J, et al. Age and sex related study of hepatitis $\mathbf{B}$ virus chronic carrier state in infants from an endemic area (Senegal). $\mathcal{F}$ Med Virol 1987 22: $1-5$.

8 Stevens CE, Beasley RP, Tsui J, Lee WC. Vertical transmission of hepatitis B in Taiwan. N Engl f Med 1975; 292 $771-4$.

9 Chan SH, Tan KL, Goh KT, et al. Maternal-child hepatitis $\mathrm{B}$ virus transmission in Singapore. Int $\mathcal{f}$ Epidemiol 1984; 14: 173-7.

10 Quak SH, Singh R, Oon CJ, Wong HB. The immune status of Singapore children to hepatitis B virus. Aust Paediatr of Singapore child

11 Tan CC, Guan R, Yap I, Tay HH, Kang JY. Horizontal or vertical transmission of hepatitis $B$ ? A serological survey in family members of hepatitis B carriers in Singapore. Transact Roy Soc Trop Med Hyg 1991; 85: 656-9.

12 Yap I, Wee I, Guan R. Chronic hepatitis B infection in Singapore. Sing Med f 1991; 32: 352-5.

13 Yap I, Guan R, Kang JY, Tay HH, Lee E, Choong L, Woo KT. Seroprevalence of antibodies to the hepatitis C virus in Singapore. Southeast Asian $\mathcal{f}$ Trop Med Publ Health in Singapore. South

14 Oon CJ. Liver cancer in Singapore - an overview. Sing Med f 1987; 28: 410-4.

15 Wang TL, Yap ILE, Tan YO. Hepatocellular carcinoma - a case series of 104 patients. Ann Acad Med Sing 1991; 20: 216-9.

16 Guan R, Yap I, Wong L, Tan LH, Oon CJ, Wee A Evidence of viral replication in HBsAg positive patient with hepatocellular carcinoma: measurement of serum hepatitis B virus deoxyribonucleic acid (HBV-DNA). Ann Acad Med Sing 1989; 18: 8-11.

17 Guan R, Oon CJ, Wilde C, Montesano R. A preliminary survey on aflatoxin exposure in Singapore. Ann Acad Med Sing 1986; 15: 201-5.

18 Lin Y, Shi CY, Soo BH, et al. Tumour suppresser p53 and $\mathrm{Rb}$ genes in human hepatocellular carcinoma cells. $A n n$ Acad Med Sing 1996; 25: 22-30.

19 Guan R, Kang JY. Screening for primary hepatocellular carcinoma [Editorial]. $\mathscr{F} A M A$ SEA 1995; 11: 7-8.

20 Kang JY, Guan R. Early detection of hepatocellular carcinoma. Dig Surg 1995; 12: 79-84.

21 Lok ASF, Wu PC, Lai CL, et al. Controlled trial of interferon with or without prednisolone priming for chronic hepatitis B. Gastroenterology 1992; 102: 2091-7.

22 Lai CL, Lok ASF, Lin HJ, Wu PC, Yeah EK, Yeung CY. Placebo-controlled trial of recombinant alpha 2 interferon in Chinese HBsAg carrier children. Lancet 1987; ii: in Chin

23 Guan R, Ho KY, Yap I, et al. Treatment of hepatitis B surface antigen carrier in the early stages of the infection using recombinant alpha interferon with steroid priming in Singapore. Alimentary Pharmacol Ther 1995; 9: 535-40

24 Lee BW, Yap HK, Tan M, et al. Cell-mediated immunity in patients on haemodialysis: relationship with hepatitis B carrier status. Am f Nephrol 1991; 11: 98-101.

25 Quah TC, Quak SH, Lee BW, Yap HK, Guan R. Normal cell mediated immunity in asymptomatic chronic hepatitis B virus carriers. Sing Paediatr $f$ 1995; 37: 38-42.

26 Guan R, Yap I, Seet BL. Interferon production is normal in childhood acquired chronic hepatitis B infection. Sixth Nagasaki-Singapore Symposium on Medical Sciences. Viral infection, immunity and related diseases. Nagasaki, 4 Viral infection, immunity and related dised

27 Wong D, Cheung AM, O'Rourke K, Nayor CD, Detsky AS, Heathcote J. Effect of alpha-interferon treatment in patients with hepatitis B e antigen-positive chronic hepatitis B. A meta-analysis. Ann Intern Med 1993; 119. 312-3.

28 Goh KT. Prevention and control of hepatitis B virus infection: formulation, implementation and monitoring of the hepatitis B immunization program. In: Epidemiology and control of hepatitis B virus infection in Singapore. Southeast Asian Medical Information Centre, Tokyo, Southeast Asian Medical Information Centre,

29 Goh KT. Prevention and control of hepatitis B virus infection: follow-up of children and adults who have been vaccinated against hepatitis B. In: Epidemiology and control of hepatitis B virus infection in Singapore. Southeas Asian Medical Information Centre, Tokyo, Japan SEAMIC Publication 1992; 65: 210-35.

$30 \mathrm{Goh}$ KT. Clinical trials on hepatitis B vaccine: evaluation of the immune response and safety of reduced doses of a yeast derived hepatitis $B$ vaccine. In: Epidemiology and yeast derived hepatitis B vaccine. In: Epidemiology and Southeast Asian Medical Information Centre, Tokyo, Japan. SEAMIC Publication 1992; 65: 184-95.

31 Guan R, Yap I, Tay HH. Hepatitis B vaccination: half dose recombinant DNA hepatitis B vaccine (B-hepavac II) is as immunogenic as the full recommended dose in healthy adults. F Gastroenterol Hepatol 1991; 6: 374-6.

32 Guan R. Persistence of anti-HBs with different doses of hepatitis $B$ vaccine and the effect of small booster doses in those with undetectable anti-HBs levels: a three yea study. Epidemiological News Bulletin 1992; 18: 13-4.

33 Pol S, Driss F, Carnot F, Michel ML, Berthetot P, Brechot C. Vaccination against hepatitis $B$ virus: an efficient immunotherapy against hepatitis B multiplication. $C R$ Acad Sci Paris, Life Sciences 1993; 316: 688-91.

Acad Sci Paris, Life Sciences 1993; 316: 688-91.
34 Carman WA, Zanetti A, Karayiannis P, et al. Vaccine induced escape mutant of hepatitis B virus. Lancet 1990 336: 325-9.

35 Harrison TJ, Hopes EA, Oon CJ, Zanetti AR, Zuckerman AJ. Independent emergence of a vaccine induced escape mutant of hepatitis B virus. F Hepatol 1991; 13: S105-7. 